\title{
Short Term Clinical Results of Single Injection Autologous BMAC (Bone Marrow Aspirate Concentrate) As A Therapeutic Option/Tool in Knee Osteoarthritis
}

\section{Krishna Subramanyam}

Yashoda Super Specialty Hospitals Malakpet Hyderabad

Subhadra Poornima ( $\sim$ subhadrapoornima1@gmail.com )

Kamineni Academy of Medical Sciences and Research Centre

\section{Satish Kumar}

Yashoda Super Specialty Hospitals Malakpet Hyderabad

Qurratulain Hasan

Kamineni Academy of Medical Sciences and Research Centre

\section{Research}

Keywords: Knee Osteoarthritis, Bone marrow, Autologous, Injection, Unilateral, X-Rays, MRI

Posted Date: May 11th, 2021

DOl: https://doi.org/10.21203/rs.3.rs-497850/v1

License: (c) (1) This work is licensed under a Creative Commons Attribution 4.0 International License.

Read Full License 


\section{Abstract}

Background: Knee Osteoarthritis (KOA) is a common degenerative joint disease characterized by loss of articular cartilage, osteophyte formation, resulting in disability and affecting the quality of life. There is no treatment as on today to reverse the progression of KOA. The present available treatments for KOA are palliative. Therefore, there is a need for an alternative treatment modality in the treatment of KOA during the early grades, which should help in not only giving a symptomatic relief but also downturn the disease process. Bone marrow aspirate concentrate (BMAC) has gained a considerable importance change in the management/treatment of KOA in the recent times due to its potential advantages of disease modifying and regeneration capacities. The latest studies on usage of Autologous BMAC injection in KOA showed promising and encouraging results in terms of decrease in the pain, improved knee range of movement, daily activities of living and thus improved expectations for good quality lives. The current study aimed to assess the role of single injection-autologous BMAC as a therapeutic option in the treatment of KOA and evaluate the functional and clinical outcome of KL grade II\&III patients.

Methods: One Hundred and thirty-two patients with KOA (KL grade II\&III) were included in the study as per the inclusion criteria. Autologous Bone marrow aspiration was done and the separation was done using density gradient centrifugation and final aspirate was injected into the knee joint.

Results: The clinical outcomes of the patients were evaluated at different time points both objectively [Visual Analogue Scale (VAS) \& WOMAC (Western Ontario Mac Master Universities Score)] and subjectively (radiographs \& MRI) and the follow up was done for a period of one year. At the end of the study period, BMAC therapy showed promising results with encouraging clinical outcome.

Conclusion:BMAC therapy has more potential with satisfactory, efficient and durable results in KOA. $\mathrm{BMAC} /$ mononuclear cells with enriched stem cell therapy can be an alternative therapy as an early intervention option for knee osteoarthritis.

\section{Background:}

Knee Osteoarthritis (KOA) is degenerative disorder and progressive disabling disease affecting people in 4th decade and above age [Sharma, 2021]. Patients with symptomatic Knee Osteoarthritis (KOA), ranges from $10-13 \%$ in the ages of 60 years and above [Azad et al, 2017]. KOA is typically characterized by pain and limitations in joint mobility, dexterity and functional ability. Patients with KOA have reduced ability to work and participate in social roles with associated impacts. The present non-surgical treatment modalities of KOA are life style modifications, external bracing, non-steroidal anti-inflammatory drugs (NSAIDs), disease modifying Osteoarthritic drugs (DMODS) and intraarticular steroids and Hyaluronic acid [Mora JC et al 2018]. Conventional clinical treatment in KOA may not address to get the final successful outcome. The present available treatments for knee Osteoarthritis are palliative. Therefore, there is a need for an alternative treatment modality in the treatment of KOA during the early grades, which should help in not only giving a symptomatic relief but also downturn the disease process. The 
scope of autologous Bone marrow aspirate concentrate (BMAC-Stem cell therapy) has the potential to help scientists and the clinicians devise an early interventional treatment for KOA. Current literature reviews are showing that intra articular injection of autologous BMAC has a potential in decreasing the symptoms and functional improvement of the osteoarthritic knee joint [Gobbi et al, 2011]. It may work by modifying the underlying disease process and slackening the progress of KOA.

In recent years there is an increasing interest in usage of autologous Bone marrow aspirate concentrate (BMAC)/stem cells in different musculoskeletal conditions [Zlotnicki et al, 2016, Laprade et al, 2016]. The latest studies on usage of Autologous BMAC injection in KOA showed promising and encouraging results in terms of decrease in the pain, improved knee range of movement, daily activities of living and thus improved expectations for good quality lives. These results with autologous BMAC are long lasting than other non surgical treatments and also showed better safety profiles [Prodromos C et al, 2020; Kim GB et al 2020; Gursoy S et al 2019; Oliver KS et al, 2019; Cavallo C et al, 2020].

Stem cells are the basic human cells that have potential to give rise to many different cell types, they are simple and differentiated. These will help to create new cells in existing healthy tissue and may help to repair in those structures that are injured or damaged. When they divide, they create progenitor cells and these will become cells with more specialized tissue structures such as bone and cartilage. The two most common sources of stem cells for clinical application in Orthopedics are bone marrow and adipose tissue [GI Im2017].

BMAC is a combination of mesenchymal stem cells (MSC) and hemopoietic stem cells, endothelial progenitor cells and growth factors [Gursoy S et al, 2019]. There is a strong evidence that MSC's and the growth factors present in BMAC helps in regeneration of the diseased cartilage with respect to increase in cartilage volume [Acharya $\mathrm{C}$ et al, 2012]. In the current study single injection of intraarticular autologous BMAC is given for patients with Primary Knee Osteoarthritis (KL grade II\& III) and the clinical outcomes of this treatment are studied.

The current study aimed to assess the role of single injection- autologous BMAC as a therapeutic option in the treatment of knee osteoarthritis and evaluate the functional and clinical outcome of KL grade II\&III patients.

\section{Methods:}

Patients who received a single injection of BMAC for the treatment of symptomatic unilateral/bilateral knee joint (s) between March 2013- October 2016 were recruited in this study.

\subsection{Patient Recruitment:}

One Hundred and thirty-two patients with KOA (KL grade II\&III) [Figure 1] were included and the study was conducted at Kamineni Hospitals LB Nagar \& Yashoda Hospitals Malakpet, Hyderabad, India. The study duration was between March 2013- October 2016. All Patients were counseled by a Lead Surgeon and 
Certified Genetic Counselor about the autologous BMAC injection as a treatment option. Institutional Stem cell Ethics Committee approved this study. The recruitment of all the patients was done after obtaining a written consent [Figure-2].

Exclusion Criteria for the study:

- KOA patients with $\mathrm{KL}$ grade 1 \& 4

- KOA Patients with deformities, knee instabilities

- Infective Arthritis and

- Metabolic Arthritis

\subsection{Methodology:}

\subsubsection{Bone Marrow Aspiration:}

In all the patients, autologous bone marrow was aspirated under sterile aseptic conditions and harvested from posterior iliac crest. In operating room, patient was positioned in lateral position, the iliac wing is covered under ' $O$ ' drape, under local anesthesia $60 \mathrm{ml}$ of bone marrow was aspirated using 14 Gauge bone marrow aspiration needle and collected into falcone tubes which were flushed with ACD (Anticoagulant citrate dextrose). Aspiration was done by single surgeon for all the cases (Fig. 3A). In cases of patients with bilateral KOA, bone marrow was aspirated from both the iliac crests separately. The collected bone marrow was processed by density gradient centrifugation method (Fig. 3B).

\subsubsection{Density gradient centrifugation method for Separation of mononuclear cells enriched with stem cells:}

After the aspiration, bone marrow was transferred to sterile Falcone tubes flushed with ACD and processed using density gradient centrifugation method. Ficoll and sample was taken in 1:1 ratio and centrifuged. Total RBC was settled at the bottom and the serum was separated on the top. Buffy coat (creamy middle layer) was aspirated. Cell suspension was washed twice with the DPBS Cell yield was counted. Approximately 7cc (6-8cc) of BMAC (final mononuclear cells enriched with stem cells) was obtained [Themistocleous et al, 2018]. The obtained BMAC was injected into the knee joint through the antero-lateral portal using 20 gauge needle while knee is in flexion under strict aseptic precautions. A compression bandage was applied in all the patients following the injection and post injection knee ROM (Range Of Movement) exercises were initiated for the uniform spread of BMAC intraarticularly. All the patients were injected by a single Surgeon (Fig. 3C). During the initial part of the study, we had performed flow cytometry, to characterize MSC's using specific CD markers (both positive and negative) in final BMAC before injecting to the patient [Sundber et al, 2018]. Positive markers CD105, CD 90 \& negative markers CD34, CD45 were used. We found an average of $85-90 \%$ of positive CD markers in all the samples that were studied (Fig. 4). 


\subsubsection{Outcome Measurements:}

The patient outcome measurements were assessed by the following:

1. Subjective: Visual Analogue Score (VAS) and Western Ontario and Mc Master Universities Osteoarthritis Index (WOMAC).

2. Objective: Standing Radiographs of knee and Knee MRI in $30 \%$ of patients to assess the cartilage volume.

All the patients were assessed both subjectively and objectively at the end of 3rd, 6th and 12 months and the results were assessed. In all the patients, post autologous BMAC injection selective COX2 inhibitors were advised for pain as and when required. All patients were advised weight relieving exercises like stationary bike/cycling.

\section{VAS Score}

VAS indicates the degree of pain intensity. It is indicated from 1 to 10 where 1 indicates no pain, 2-4 is mild pain, and 5-7 is moderate pain and above 7 is considered as severe pain.

\section{WOMAC Score}

WOMAC is widely used in evaluation of Knee and Hip Osteoarthritis. WOMAC is a self-administered questionnaire to assess sub scale of pain, stiffness and Physical/ functional activities- like sitting down, bending to the floor, walking on flat surface etc. WOMAC Index for the patients was scored for 96 points which is subdivided and summed up, for Pain 0-20, stiffness 0-8 and for Physical function 0-68 (Overall WOMAC Index scored for 98). No patient had adverse effects following the injection. Standing Radiographs of the knee joint were recommended for all the patients, however due to the cost constraints MRI was performed in $30 \%$ of patients only.

\section{Results}

3.1 Baseline Characteristics: Total of 132 patients were included in the present study and evaluated based on the eligibility criteria. Post injection, all patients were followed for one year and at interval 3rd, 6th and 12 months and evaluated by VAS, WOMAC scores. Standing knee radiographs were obtained at the end of 12th month in all patients (Table 1).

3.2 Pain Score details: In all patients, the severity of pain was evaluated using VAS score and functional knee score was evaluated by WOMAC at the end of 3rd, 6th and 12 months.

3.3 Functional and Clinical Outcome: The Symptoms of all patients were evaluated in both pre and post injection up to 12 months. All Patients were followed up for a period of one year. The amount of reduction in symptoms, regular daily activities like climbing stairs, rising from chair, squatting, walking comfort and 
the amount of activity of daily living that patient had regained back without any knee discomfort were assessed.

3.4. Radiological Observations: All patients underwent radiographic examination of both knees (weight bearing) anterio-posterior and lateral views before BMAC Injection and at the end of 12 months following the injection. Radiographs were read and scored by radiologist and Orthopaedic Surgeon blinded to the patient's clinical information using $\mathrm{KL}$ grade system.

Table 1

Details of the study for autologous BMAC administration and final clinical outcome

\begin{tabular}{|c|c|c|c|c|c|c|}
\hline S. & No of patients & Treatment & $\begin{array}{l}\text { Harvest } \\
\text { Site }\end{array}$ & $\begin{array}{l}\text { Delivery } \\
\text { Method/BMAC } \\
\text { Injected } \\
\text { Amount }\end{array}$ & $\begin{array}{l}\text { Follow } \\
\text { Up } \\
\text { period }\end{array}$ & $\begin{array}{l}\text { Outcome / Adverse } \\
\text { Events }\end{array}$ \\
\hline \multirow[t]{2}{*}{1} & \multirow[t]{2}{*}{$\begin{array}{l}\text { Patients with } \\
\text { Unilateral KOA } \\
(n=106)\end{array}$} & \multirow[t]{2}{*}{$\begin{array}{l}\text { Single } \\
\text { Injection } \\
\text { of BMAC }\end{array}$} & \multirow[t]{2}{*}{$\begin{array}{l}\text { Iliac- } \\
\text { crest }\end{array}$} & $\begin{array}{l}\text { Intra-articular } \\
\text { injection } \\
7 \mathrm{ml} \text { of BMAC }\end{array}$ & \multirow[t]{2}{*}{$\begin{array}{l}12 \\
\text { Months }\end{array}$} & $\begin{array}{l}\text { There was } \\
\text { significant } \\
\text { improvement in pair } \\
\text { and function. }\end{array}$ \\
\hline & & & & $7 \mathrm{ml}$ of BMAC & & $\begin{array}{l}\text { No Adverse Events } \\
\text { were reported }\end{array}$ \\
\hline \multirow[t]{3}{*}{2} & \multirow{3}{*}{$\begin{array}{l}\text { Patients with } \\
\text { Bilateral KOA } \\
(\mathrm{n}=26)\end{array}$} & \multirow{3}{*}{$\begin{array}{l}\text { Single } \\
\text { Injection } \\
\text { of BMAC }\end{array}$} & \multirow[t]{3}{*}{$\begin{array}{l}\text { Iliac- } \\
\text { crest }\end{array}$} & $\begin{array}{l}\text { Intra-articular } \\
\text { injection }\end{array}$ & \multirow[t]{3}{*}{$\begin{array}{l}12 \\
\text { Months }\end{array}$} & \multirow{2}{*}{$\begin{array}{l}\text { There was } \\
\text { significant } \\
\text { improvement in pain } \\
\text { and function. }\end{array}$} \\
\hline & & & & \multirow{2}{*}{$\begin{array}{l}7+7 \mathrm{ml} \text { of } \\
\text { BMAC }\end{array}$} & & \\
\hline & & & & & & $\begin{array}{l}\text { No Adverse Events } \\
\text { were reported }\end{array}$ \\
\hline
\end{tabular}

\subsection{Clinical Outcome:}

The total numbers of patients included were 132 and the percentage of females and males were 70\% (92) and $30 \%$ (40) respectively. The percentage of patients with unilateral and bilateral knees KOA are $80 \%$ (106) \& $20 \%$ (26) respectively. Severity of knee osteoarthritis was scored by KL grading in all the patients. $50 \%(66)$ of patients were $\mathrm{KL}$ grade II and $50 \%(66)$ were $\mathrm{KL}$ grade III. All the patients with $\mathrm{KL}$ grade III had a pre injection VAS score of 8 and 9 with disability to attend most of their daily activities, where as $90 \%$ of the $\mathrm{KL}$ grade II had a pre injection VAS score of 6 and 7 with difficulty in climbing stairs and perform high demand activities of knee like squatting. After proper counseling and consent, BMAC injection was administered to the patients. Patients were suggested post injection weight relieving (stationary bike and swimming) and pain medication as anwhen necessary (selective COX2 inhibitors). Following the BMAC injection all patients showed beginning in the improvement of pain as early as from the end of 3rd month and showed steady improvement in their VAS scores and at the end of 6 months their VAS scores reached as low as $0-1$ and which is consistently lasted till the end (Fig. 5). At the end of one year $95 \%$ of the patients got complete pain free and no individuals with severe pain indicating a significant outcome with this therapy/treatment (Fig. 6). 
In all 132 patients, improvement of pain was observed as early as at the end of 3rd month following BMAC injection to an extent of $75 \%$ compared to pre injection by VAS and steadily improved to almost complete relief of pain by the end of 6th months. This pain relief was lasted till the end of 12 months (final follow up) in $95 \%$ of (125) them and remaining 5\% (7) patients started experiencing pain (VAS 5 to 6) with high demand activities like climbing stairs and squatting during the final follow up. All these 7 patients belong to $\mathrm{KL}$ grade III.

WOMAC SCORE: Accounts for $7(10 \%)$ patients with pain with high demand activities at the final followup for $\mathrm{KL}$ grade III patients $(\mathrm{N}=66)$ (Table 2).

Table 2

Percentage of clinical outcome of Knee Osteoarthritis patients assessed with WOMAC Score

\begin{tabular}{|c|c|c|c|c|c|c|c|c|}
\hline \multirow{3}{*}{$\begin{array}{l}\text { WOMAC } \\
\text { Index } \\
\text { Score } \\
(0-96)\end{array}$} & \multicolumn{4}{|c|}{ KL Grade II $(n=66)$} & \multicolumn{4}{|c|}{ KL Grade III $(n=66)$} \\
\hline & \multirow{2}{*}{$\begin{array}{l}\text { Pre } \\
\text { Injection }\end{array}$} & \multicolumn{3}{|c|}{ Post Injection } & \multirow{2}{*}{$\begin{array}{l}\text { Pre } \\
\text { Injection }\end{array}$} & \multicolumn{3}{|c|}{ Post Injection } \\
\hline & & $\begin{array}{l}3 \\
\text { Months }\end{array}$ & $\begin{array}{l}6 \\
\text { Months }\end{array}$ & $\begin{array}{l}12 \\
\text { Months }\end{array}$ & & $\begin{array}{l}3 \\
\text { Months }\end{array}$ & $\begin{array}{l}6 \\
\text { Months }\end{array}$ & $\begin{array}{l}12 \\
\text { Months }\end{array}$ \\
\hline Mild (<35) & 0 & 100 & 100 & 100 & 0 & 60 & 100 & 90 \\
\hline $\begin{array}{l}\text { Moderate } \\
(36-75)\end{array}$ & 100 & 0 & 0 & 0 & 25 & 40 & 0 & 10 \\
\hline $\begin{array}{l}\text { Severe } \\
(75-96)\end{array}$ & 0 & 0 & 0 & 0 & 75 & 0 & 0 & 0 \\
\hline
\end{tabular}

\subsection{Objective assessment:}

In all patient's weight bearing knee Radiographs (both AP \& lateral) were taken pre injection and at the end of 12th month following the BMAC injection. There are 66 patients $(50 \%)$ in $\mathrm{KL}$ II and 66 patients $(50 \%) \mathrm{KL}$ III. At the end of 12 th month following the BMAC injection initially, all patients with $\mathrm{KL}$ grade II and $85 \%$ (56) of patients with KL grade III remained in the same KL grade, where as $15 \%$ (10) of patients in $\mathrm{KL}$ grade III have improved to $\mathrm{KL}$ grade II with opening of medial joint space as shown in the final radiographs (Fig. 7).

We have performed MRI of knee joint in 30\% (40) of patients before injection and at the end of 12th month following BMAC injection. All patients in whom MRI of knee was performed belonged to KL grade III. Among these, in 10 patients there is improvement of cartilage volume by about 20 to $30 \%$ at the end of 12th month as compared to pre injection MRI of the patient. This evidences the regeneration of cartilage and improvement of radiographic grade from $\mathrm{KL}$ grade III to II in these 10 patients after BMAC injection.

\section{Discussion}


BMAC/ Stem cell therapy has opened a new horizon in the treatment of KOA and may in future shift the paradigm in the clinical practice. Stem cell research arose from the need to explore the new therapeutic possibilities for Orthopaedic related problems [Granero Molto et al, 2008, Davatchi.F et al, 2011]. $\mathrm{BMAC} /$ Stem cell therapy can be applied to the problems related to bone, cartilage and tendon regeneration. In the Orthopedics field, for the diseases which current treatment modalities do not offer satisfactory, efficient or durable results may be targets of stem cell treatment [Sampson et al, 2015]. BMAC/Stem cell treatment may provide an innovative, cost effective and reliable therapy for knee osteoarthritis [Im 2016; Vanatier et al 2009].

During the recent years there is an increasing interest in using intra articular BMAC injection in the treatment of KOA. BMAC is essentially a combination of cellular component, soluble growth factors and cytokines. The cellular component of BMAC contains various MSCs, haemopoietic precursors, monocytes and endothelial cells. BMSCs exhibit immune modulatory, anti-inflammatory, proliferative and chemo attractive functions. Therefore, BMACs can induce the differentiation process of cellular regeneration in the osteoarthritis knee joint. Various growth factors present in BMAC like TGF beta, VEGF, BMP2, IL 1ra and platelet derived growth factors work on the various cellular pathways essential in the regulation of cell catabolic and pathways [Cavallo $\mathrm{C}$ et al, 2020].

Therefore, the combination of cellular component and various biologically active proteins makes BMAC a unique orthobiological treatment modality by not only reducing the pain in KOA, but also has the potential to alter the disease progress.

The advantages of BMAC are ease of obtainability (aspiration from iliac crest), no need for culture and cell expansion, no or reduced risk of infection (point of source processing and injection) and no risk of allogeneic disease. With all these advantages the usage of BMAC as a treatment modality in KOA is rapidly growing and gaining popularity [Cavallo $\mathrm{C}$ et al, 2020].

Earlier studies showed good results, where the bone marrow stem cells were used in Knee Osteoarthritis (Tibiofemoral and patellofemoral joints) and isolated osteochondral lesions, with a follow up of 12-24 months [Wakitani et al, 2007; Kuroda et al, 2007; Haleem et al, 2010; Kasemijwattana et al, 2011; Giannini et al, 2009; Giannini et al, 2010; Gobbi et al,2011; de Windt et al, 2016]. Latest studies in the literature have uniformly emphasized on the safety and benefit of intrarticular injection of autologous BMAC in KOA [Mautner, 2019; Cavallo C et al, 2020].

In the current study, single injection of intraarticular autologous BMAC (rich in BMSCs) was administered into the KOA joints in 132 patients (KL grade II and III) and evaluated the functional and clinical results both objectively and subjectively for a period of 12 months. We found that there is a uniform improvement of pain score and activity of daily living (quality of life) following the BMAC injection and sustained relief of pain even at the end of 12 months in 125 patients. In 7 patients with KL grade III, persistence of knee pain with high demand activities like stairs climbing and squatting needing to use occasional COX2 inhibitors for pain relief. 
10 patients out of 132 (13\%) showed increased knee joint space and improved KL grade from 3 to 2 in Post BMAC injection weight bearing knee radiographs at the end of 12th month as compared to pre injection radiographs (Fig. 7). Rest of the patients remained in the same KL grades. In 10 patients, the follow up knee MRI at the end of 12th month, there is an increased cartilage volume ( 20 to $30 \%$ ) of the knee was also observed. No adverse events were observed in any of the patients following BMAC injection. Therefore, the current study showed both subjective and objective improvement in all the patients following single intrarticular autologous BMAC injection in KL grade II and KL grade III KOA patients.

Other studies from the literature, Shapiro, 2016; Garay-mendoa, 2018; Mautner, 2019; also conducted BMAC injection for KOA patients however, our study duration follow up was long i.e 12 months whereas other studies followed up till 6 months. Recent study of Anz et al, 2020 was almost similar, but in the current study both subjective assessment by VAS and WOMAC scores was done for the period of 12 months and objective assessment by $X$ - rays and MRI was novel feature of our study.

\subsection{The unique features / highlights of the current study:}

We recruited KOA patients with $\mathrm{KL}$ grade II \& III as compared to $\mathrm{KL}$ grade I\&II in most of the studies in the literature. The number of patients was equal in both $\mathrm{KL}$ grades groups. We have given a single injection of autologous BMAC harvested from iliac crest. Post injection all patients were followed both subjectively and objectively with weight bearing knee radiographs and in $30 \%$ of patients Knee MRI was done to know the cartilage volume, where as in most of the studies only subjective assessment of post injection results was done.

\section{Conclusion:}

BMAC therapy has potential implications in the treatment of mild to moderate KOA in terms of pain reduction, avoiding the need of analgesics and slowing the degenerative process \& regeneration in the diseased cartilage with satisfactory, efficient and durable results. BMAC/mononuclear cells with enriched stem cell therapy can be an alternative therapy with early intervention option. This preliminary study showed a promising result however, the study can be done in large cohort and different ethnic groups for better understanding. To the best of our knowledge this is the first study in India.

\section{Abbreviations}

OA: Osteoarthritis

KOA: Knee Osteoarthritis

BMAC: Bone Marrow Aspirate Concentrate

KL: Kellgren \& Lawrence 
ACD: Anticoagulant Citrate Dextrose

MRI: Magnetic Resonance Imaging

NSAID: Non-Steroidal Anti-Inflammatory Drugs

VAS: Visual Analogue Scale

WOMAC: Western Ontario Mac Master Universities Index Score

\section{Declarations}

\section{Ethical Approval and Consent to participate:}

The study got the approval from Institutional Stem cell Ethics Committee for Stem cell Research and Regenerative Medicine, Kamineni Hospitals, LB Nagar, and Hyderabad, India. All Patients were counseled by a Lead Surgeon and Certified Genetic Counselor about the autologous BMAC injection and the recruitment was done after obtaining a written consent.

Consent for Publication: Not applicable

Availability of data and Materials: Not Applicable

Competing interest: There is no competing interest to the study.

Funding: we have not received any financial support from the government academic institutions, private organizations or non-profit sectors. We appreciate encouragement from Kamineni Hospitals and Yashoda hospitals, Hyderabad for the support as a when required.

Authors Contribution: KS planned the study, obtained clinical information and recruitment of clinical cases, aspiration of bone marrow, administration of BMAC injection and follow up of the patients, analysis of results, editing of the manuscript; SP wrote the first draft of the manuscript, separation of bone marrow aspirate concentrate procedure, curation of the data, preparation of tables and figures, analysis of results, editing of manuscript; SK assisted in patient recruitment, aspiration of bone marrow; QH supervised the project and helped in the final editing of the manuscript for the scientific betterment.

Acknowledgement: We extend our sincere gratitude to all the subjects who participated in the study.

\section{References}

1. Azad CS, Singh SinghAK1,PandeyP, Tia.N MChaudharyP. Rastogi. A, Indrajeet Singh Gambhir.Osteoarthritis in India: An epidemiologic aspect. International Journal of Recent Scientific Research. 2017:8 (10): 20918-20922. 
2. Cavallo C, Boffa A, Andriolo L, Silva S, Grigolo B, Zaffagnini S, Filardo G. Bone marrow concentrate injections for the treatment of osteoarthritis: evidence from preclinical findings to the clinical application. International Orthopaedics. 202013:1-4.

3. Centeno CJ, Busse D, Kisiday J, Keohan C, Freeman M, Karli D. Regeneration of meniscus cartilage in a knee treated with percutaneously implanted autologous mesenchymal stem cells. Medical hypotheses. 2008;71(6):900-8.

4. Davatchi F, Abdollahi BS, Mohyeddin M, Shahram F, Nikbin B. Mesenchymal stem cell therapy for knee osteoarthritis. Preliminary report of four patients. Int J Rheum Dis. 2011;14(2):211-5.

5. de Windt TS, Vonk LA, Slaper-Cortenbach IC, van den Broek MP, Nizak R, van Rijen MH, de Weger RA, Dhert WJ, Saris DB. Allogeneic mesenchymal stem cells stimulate cartilage regeneration and are safe for single-stage cartilage repair in humans upon mixture with recycled autologous chondrons. Stem Cells. 2017;35(1):256-64.

6. Giannini S, Buda R, Cavallo M, Ruffilli A, Cenacchi A, Cavallo C, Vannini F. Cartilage repair evolution in post-traumatic osteochondral lesions of the talus: from open field autologous chondrocyte to bonemarrow-derived cells transplantation. Injury. 2010;41(11):1196-203.

7. Giannini S, Buda R, Vannini F, Cavallo M, Grigolo B. One-step bone marrow-derived cell transplantation in talar osteochondral lesions. Clinical Orthopaedics Related Research®. 2009;467(12):3307-20.

8. Gobbi A, Karnatzikos G, Scotti C, Mahajan V, Mazzucco L, Grigolo B. One-step cartilage repair with bone marrow aspirate concentrated cells and collagen matrix in full-thickness knee cartilage lesions: results at 2-year follow-up. Cartilage. 2011;2(3):286-99.

9. Granero-Molto F, Weis JA, Longobardi L, Spagnoli A. Role of mesenchymal stem cells in regenerative medicine: application to bone and cartilage repair. Expert Opin Biol Ther. 2008;8(3):255-68.

10. Gursoy S, Akkaya M, Simsek ME, Bozkurt M. Functional outcomes of bone marrow aspirate concentrate application in osteoarthritis of the knee. International Journal of Research in Medical Sciences. 2019;7(2):587.

11. Haleem AM, Singergy AA, Sabry D, Atta HM, Rashed LA, Chu CR, Shewy MT, Azzam A, Aziz MT. The clinical use of human culture-expanded autologous bone marrow mesenchymal stem cells transplanted on platelet-rich fibrin glue in the treatment of articular cartilage defects: a pilot study and preliminary results. Cartilage. 2010;1(4):253-61.

12. Im GI. Clinical use of stem cells in orthopaedics. Eur Cell Mater. 2017;33:183-96.

13. Im GI. Regeneration of articular cartilage using adipose stem cells. Journal of Biomedical Materials Research Part A. 2016;104(7):1830-44.

14. Kasemkijwattana C, Hongeng S, Kesprayura S, Rungsinaporn V, Chaipinyo K, Chansiri K. Autologous bone marrow mesenchymal stem cells implantation for cartilage defects: two cases report. J Med Assoc Thai. 2011;94(3):395.

15. Kim GB, Kim JD, Choi Y, Choi CH, Lee GW. Intra-Articular Bone Marrow Aspirate Concentrate Injection in Patients with Knee Osteoarthritis. Applied Sciences. 2020;10(17):5945. 
16. Sundberg M, Jansson L, Ketolainen J, Pihlajamäki H, Suuronen R, Skottman H, Inzunza J, Hovatta O, Narkilahti S. CD marker expression profiles of human embryonic stem cells and their neural derivatives, determined using flow-cytometric analysis, reveal a novel CD marker for exclusion of pluripotent stem cells. Stem cell research. 2009;2(2):113-24.

17. Kuroda S, Sugawara Y, Deguchi T, Kyung HM, Takano-Yamamoto T. Clinical use of miniscrew implants as orthodontic anchorage: success rates and postoperative discomfort. Am J Orthod Dentofac Orthop. 2007;131(1):9-15.

18. LaPrade RF, Geeslin AG, Murray IR, MusahI V, Zlotnicki JP, Petrigliano F, Mann BJ. Biologic treatments for sports injuries II think tank-current concepts, future research, and barriers to advancement, part 1: biologics overview, ligament injury, tendinopathy. Am J Sports Med. 2016;44(12):3270-83.

19. Mora JC, Przkora R, Cruz-Almeida Y. Knee osteoarthritis: pathophysiology and current treatment modalities. Journal of pain research. 2018.

20. Oliver KS, Bayes M, Crane D, Pathikonda C. Clinical outcome of bone marrow concentrate in knee osteoarthritis. Journal of Prolotherapy. 2015;7(2):e937-46.

21. Prodromos C, Finkle S, Rumschlag T, Lotus J. Autologous Mesenchymal Stem Cell Treatment is Consistently Effective for the Treatment of Knee Osteoarthritis: The Results of a Systematic Review of Treatment and Comparison to a Placebo Group. Medicines. 2020;7(8):42.

22. Sampson S, Botto-van Bemden A, Aufiero D. Stem cell therapies for treatment of cartilage and bone disorders: osteoarthritis, avascular necrosis, and non-union fractures. PM\&R. 2015;7(4):26-32.

23. Sharma L. Osteoarthritis of the Knee. New England Journal of Medicine. 2021;7(1):51-9. 384(.

24. Shapiro SA, Kazmerchak SE, Heckman MG, Zubair AC, O'connor MI. A prospective, single-blind, placebo-controlled trial of bone marrow aspirate concentrate for knee osteoarthritis. Am J Sports Med. 2017;45(1):82-90.

25. Themistocleous GS, Chloros GD, Kyrantzoulis IM, Georgokostas IA, Themistocleous MS, Papagelopoulos PJ, Savvidou OD. Effectiveness of a single intra-articular bone marrow aspirate concentrate (BMAC) injection in patients with grade 3 and 4 knee osteoarthritis. Heliyon. 2018;4(10):e00871.

26. Vinatier C, Bouffi C, Merceron C, Gordeladze J, Brondello JM, Jorgensen C, Weiss P, Guicheux J, Noël D. Cartilage tissue engineering: towards a biomaterial-assisted mesenchymal stem cell therapy. Curr Stem Cell Res Therapy. 2009;4(4):318-29.

27. Wakitani S, Nawata M, Tensho K, Okabe T, Machida H, Ohgushi H. Repair of articular cartilage defects in the patello-femoral joint with autologous bone marrow mesenchymal cell transplantation: three case reports involving nine defects in five knees. J Tissue Eng Regen Med. 2007;1(1):74-9.

28. Zlotnicki JP, Geeslin AG, Murray IR, Petrigliano FA, LaPrade RF, Mann BJ, Musahl V. Biologic Treatments for Sports Injuries II Think Tank-current concepts, future research, and barriers to advancement, part 3: articular cartilage. Orthopaedic journal of sports medicine. 2016;4(4):2325967116642433. 
Figures
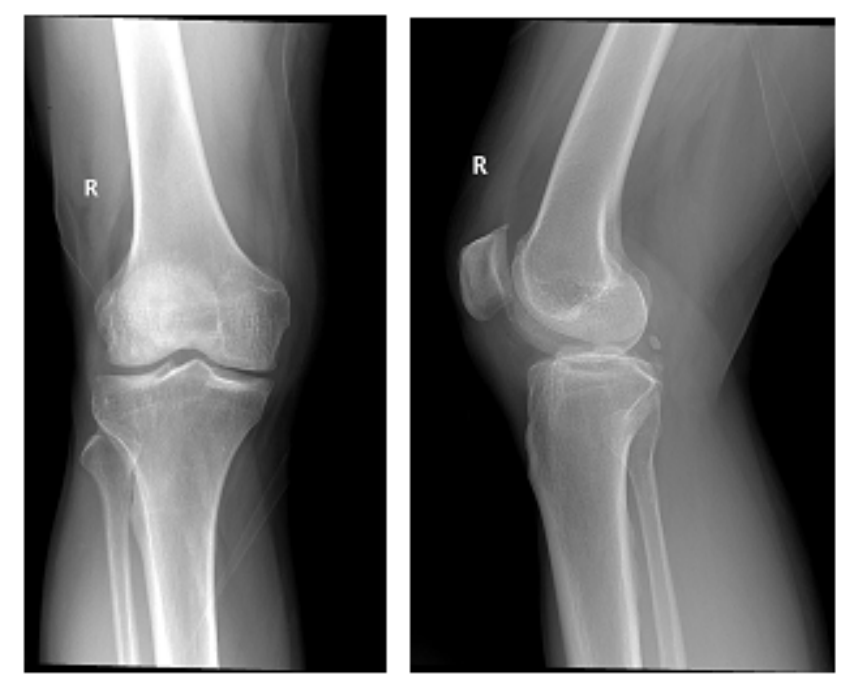

A: KL Grade II - AP \&Lateral
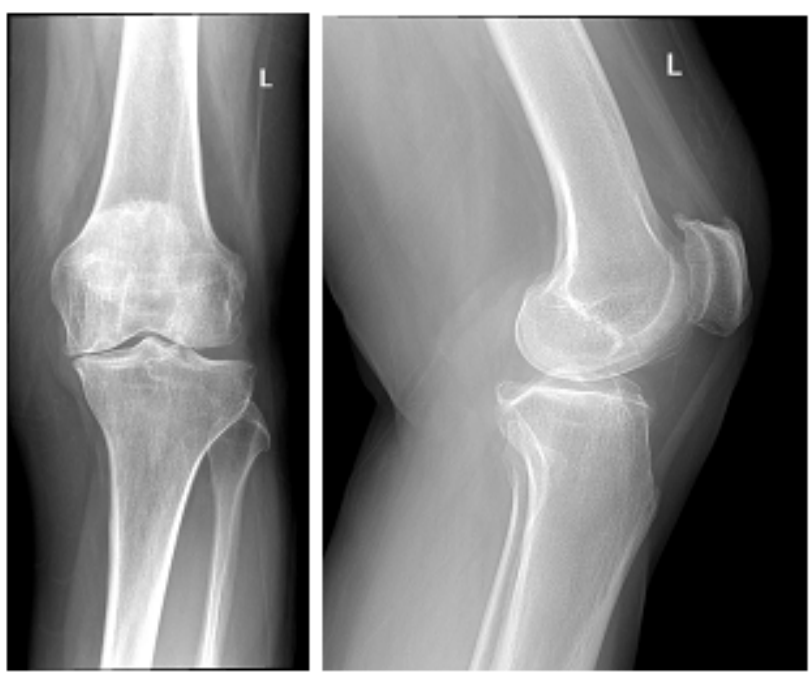

B: KL Grade III- AP \& Lateral

\section{Figure 1}

Representative Knee Osteoarthritis X - ray images of KL Grade II (AP \& Lateral) and KL Grade III (AP \& Lateral) 


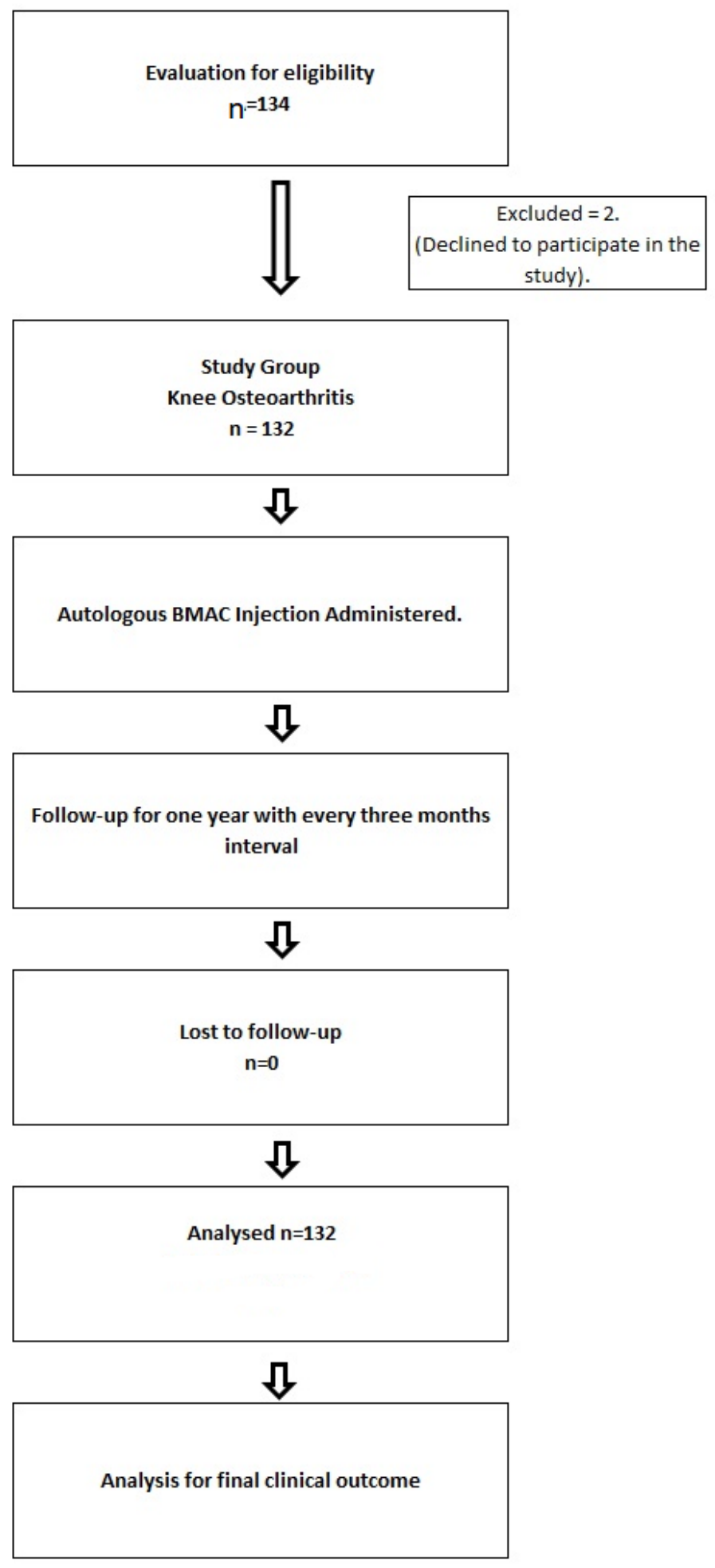

Figure 2

Work flow chart 


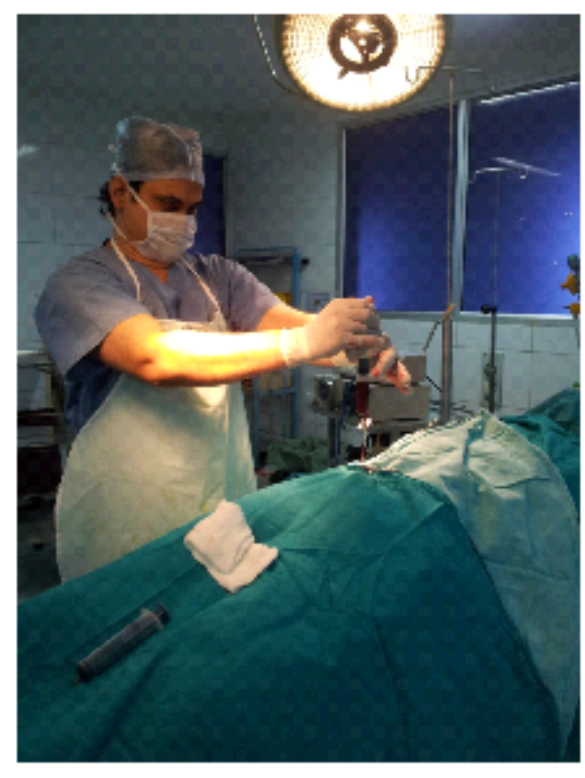

(A)

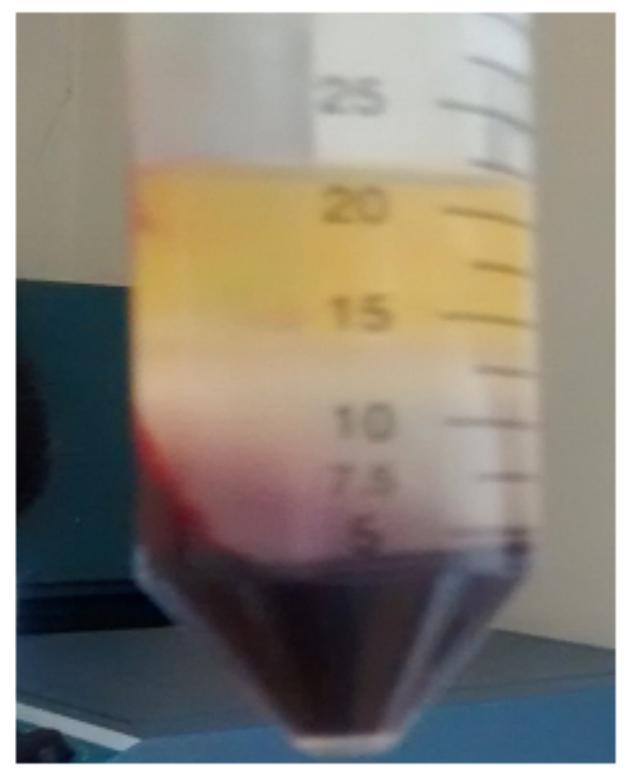

(B)

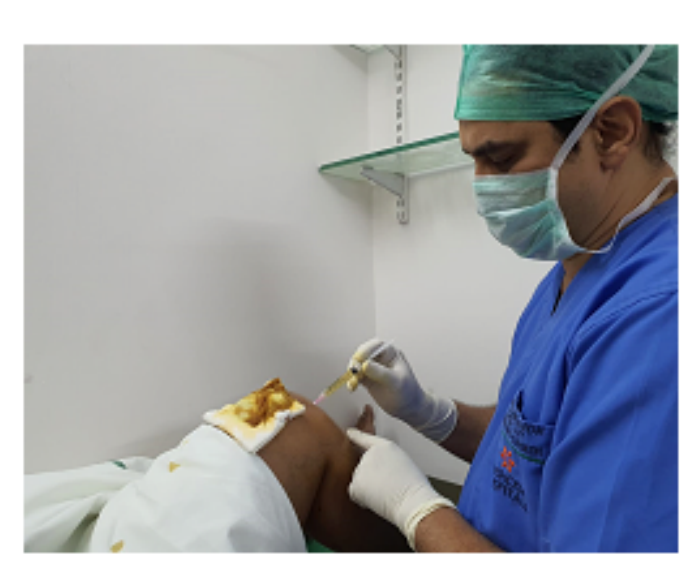

(D)

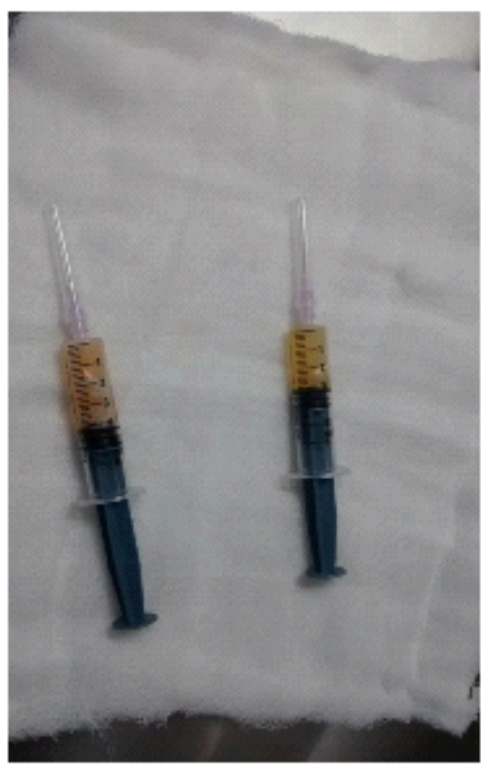

C)

\section{Figure 3}

A) Harvesting of bone marrow from patient B) Separation of bone marrow aspirate C) Separated BMAC D) Injection into the knee joint

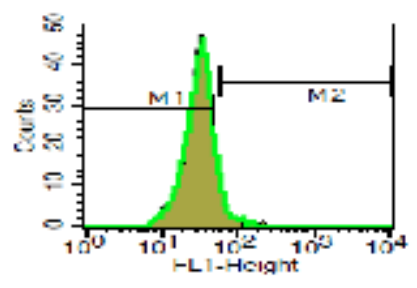

A: $\mathrm{CD}-35$

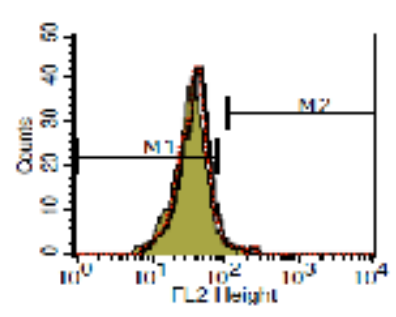

B: $\mathrm{CD}-45$

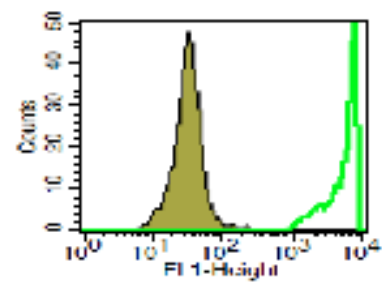

C:CD-105

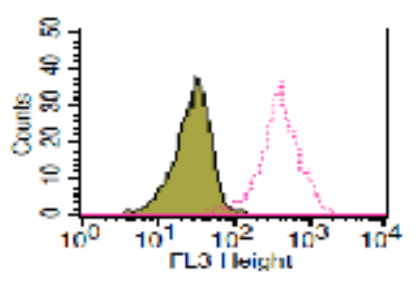

D: CD-90 


\section{Figure 4}

Flow-cytometric analysis of BMAC for both negative (CD $34 \& 45$ [A \& B]) and positive markers (CD105\&CD90 [C \& D]).

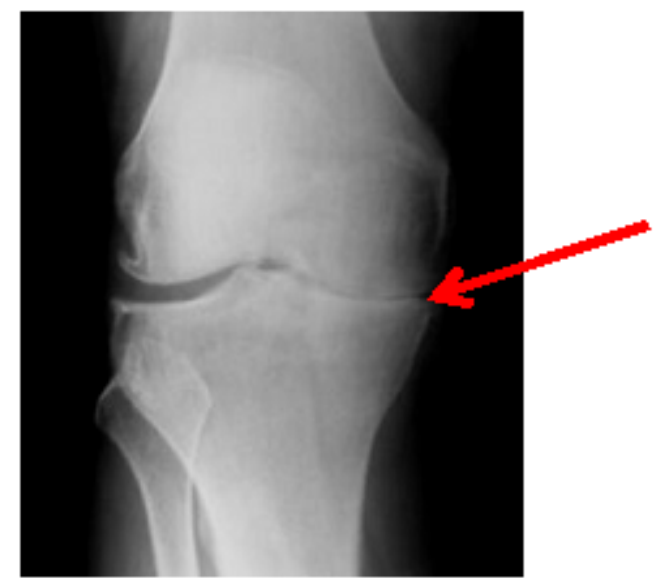

(A)

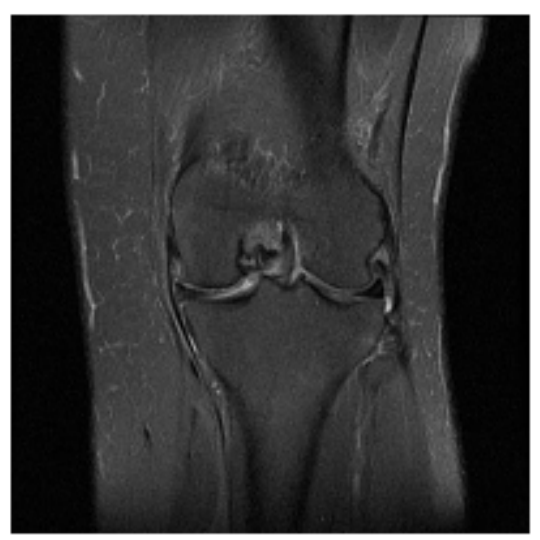

(C)

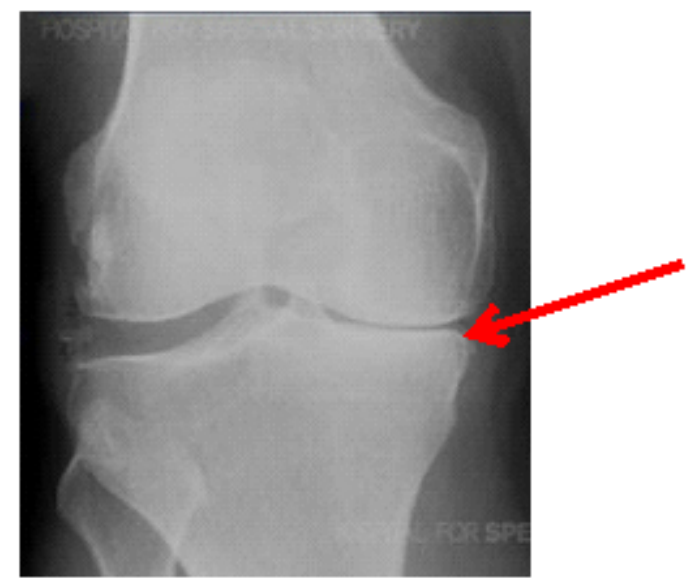

(B)

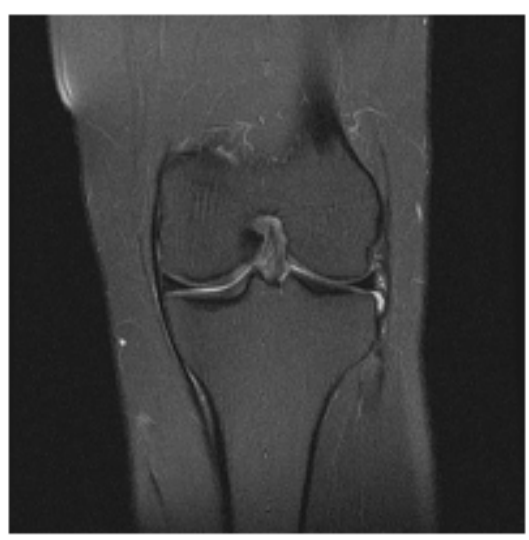

(D)

\section{Figure 5}

A) X-Ray image of pre injection with VAS score 8 (gross reduction of medial joint space) B) X-Ray image of post injection with VAS score 2 to 3 (improved medial joint space indicating cartilage regeration) C) MR image of knee -Pre injection showing KL grade III D) MR image of knee- Post Injection showing KL grade II 


\section{Clinical Outcome- VAS score}

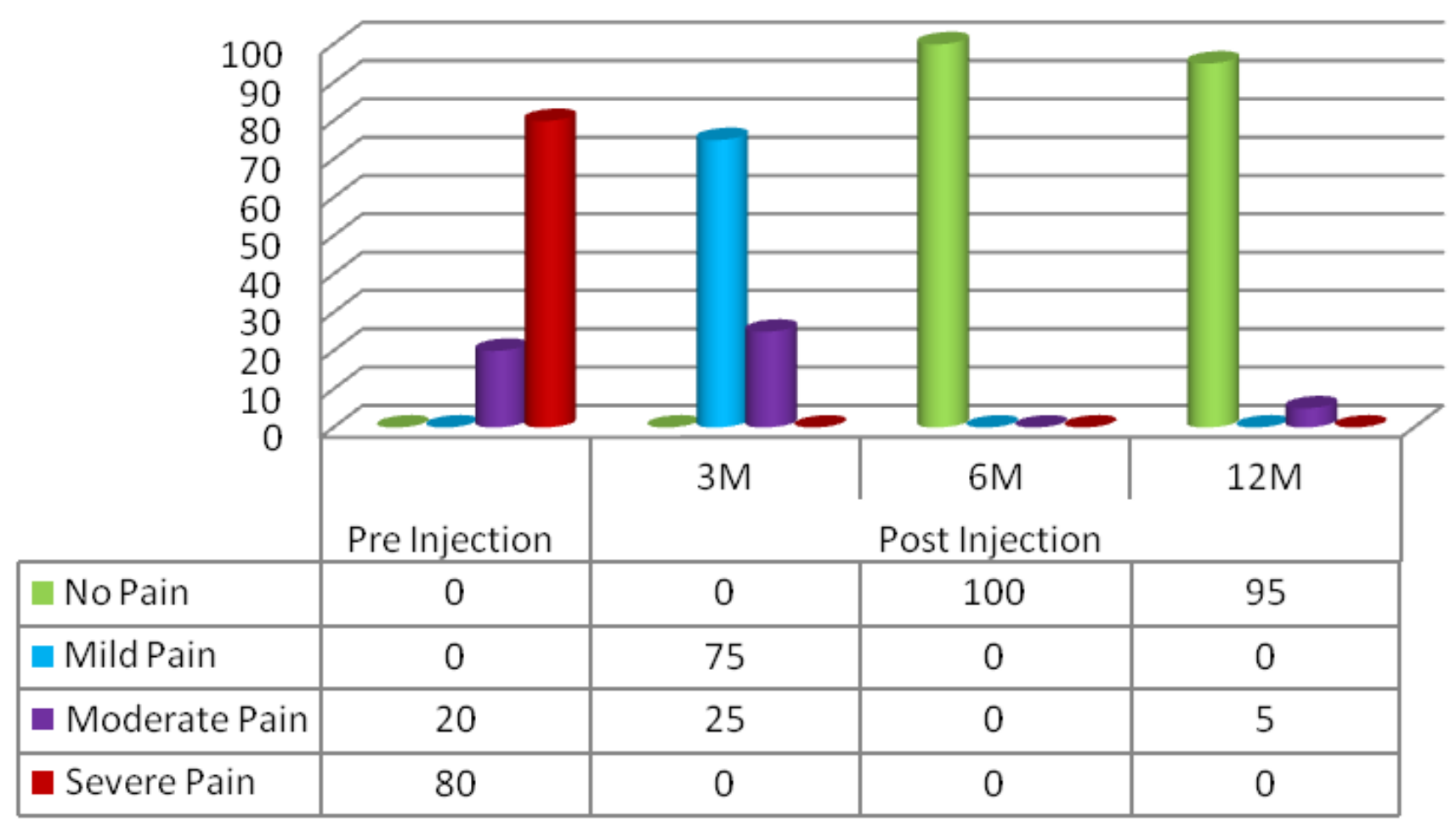

Figure 6

The percentage of clinical outcome of knee osteoarthritis group patients based on VAS
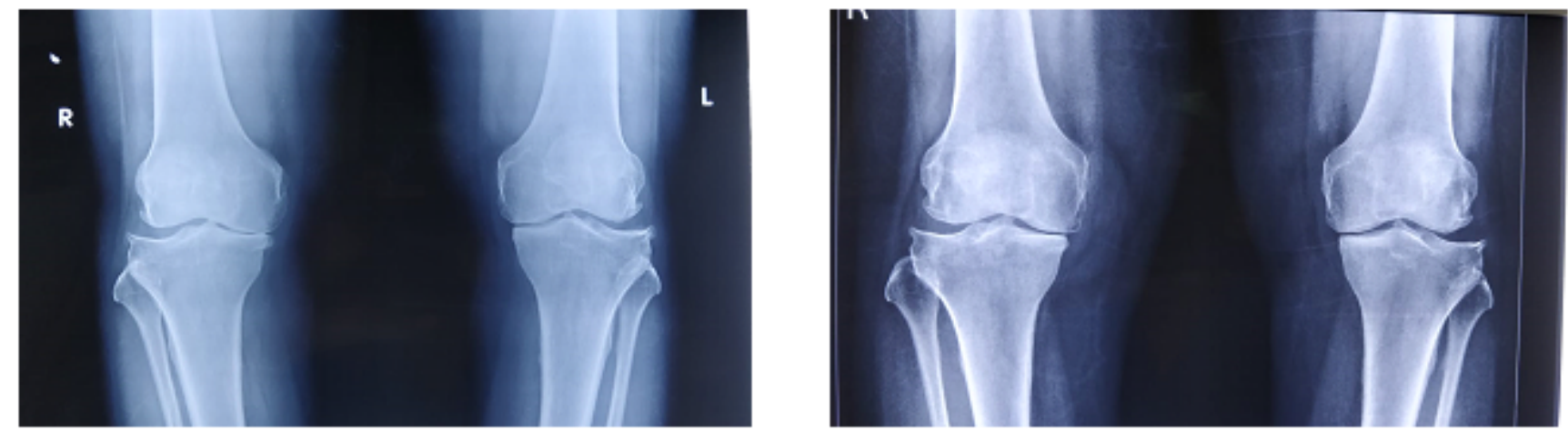
A) Pre Injection KLGrade III AP (Right- III, Left-II)
B) Post Injection Grade II AP

Figure 7

X- ray both knees weight bearing knees in 52/female, with right knee KL Grade III pre injection and post injection KL Grade II after 12 months follow up (same patient) indicating improvement in KL grading in right knee from grade III-II and left KL grade II maintained 


\section{Supplementary Files}

This is a list of supplementary files associated with this preprint. Click to download.

- SuuplimentarytableFinal.doc 